\title{
Production and Characterization of Chitosan from Shrimp Shell Waste of Parapeneopsis stylifera
}

\author{
Vijayakumar Renuka ${ }^{1}$, Chandragiri Nagaraja Rao Ravishankar ${ }^{2}$, \\ Krishnamoorthy Elavarasan ${ }^{2}$, Abubacker Aliyamveetil Zynudheen ${ }^{2}$ \\ and Toms C. Joseph ${ }^{1}$ \\ ${ }^{1}$ ICAR-CIFT Veraval research centre, Matsya Bhavan, Bhidia Plot, \\ Veraval 362 269, Gujarat, India \\ ${ }^{2}$ Central Institute of Fisheries Technology, Willingdon Island, Cochin 682 029, Kerala, India \\ *Corresponding author
}

\begin{tabular}{|l|}
\hline K e y w o r d s \\
$\begin{array}{l}\text { Chitosan, Shrimp } \\
\text { shell waste, Fourier } \\
\text { transform infrared }\end{array}$ \\
\hline Article Info \\
\hline $\begin{array}{l}\text { Accepted: } \\
17 \text { October } 2019 \\
\text { Available Online: } \\
10 \text { November } 2019\end{array}$ \\
\hline
\end{tabular}

\section{Introduction}

Chitin is the most abundant natural polysaccharide. It gives strong structure to the exoskeleton of living organism. Marine resources especially, shells of crustacean such as those from shrimp, crab and lobster are the most important chitin source for commercial purposes. It is a linear homo-polysaccharide and chemically it has several units of $n$ acetyl D- glucosamine linked by $\beta$ 1-4 linkage (Younes and Rinaudo, 2015). Chitin is not readily dissolved in water and mild acids due to the acetamide group. Though the chitin showed a various functional property, their application in many fields were restricted due 
to its high molecular weight and less solubility. This drawback leads to the finding of the chitosan from chitin in late 1850s (Crini, 2019). The important derivative of chitin is chitosan and it is partial deacetylated form of chitin. Chitosan is a rigid linear chain heteropolymer consisting of D-glucosamine $(\mathrm{GlcN})$ and N-acetyl-D-glucosamine (GlcNAc) joined by $\beta-(1,4)$-linkage. Commercial chitosan has the molecular range of 50-2000 $\mathrm{kDa}$. The ratio between the glucosamine and $\mathrm{N}$-acetyl glucosamine is called degree of acetylation. This degree of acetylation determines the chitosan's biological property. Generally the Degree of deacetylation (DD) for commercial processed chitosan was around $80-85 \%$. It is the cationic polysaccharide due to the presence of positive charges on amino group. Chitosan are dissolved in mild acids. Among the chitin derivatives, chitosan is considered as the most important derivative because of it solubility. Chitosan offer a wide range of application from the agriculture to pharmacy industry due to its specific properties like bioactivity, biodegradability, chelating ability, absorption capacity and environmental friendly (Hamed et al., 2016). Because of its cationic property it has wide range of application in industrial usage. Chitosan also possesses a number of functional properties such as antioxidant, antibacterial, cholesterol reduction agent, edible film packaging material, texturizing, flocculating agent, binding, emulsifying and clarifying agent.

Ever increasing demand of shrimp consumption in the local as well as international markets, Indian shrimp industry gained a great importance in the world seafood trade. In Indian waters there are 85 species of shrimp are recorded. Among them 55 species are considered as commercially important species which having considerable demand in market. In 2017-18, India has exported 13,77,244 tons of marine products, in which frozen shrimp contributed 65,980 ton. Along the Indian coast 581 seafood freezing plants are present, with a built in capacity of 31,006.07MT (MPEDA, 2019). Parapeneopsis stylifera is commonly called kiddi shrimp mainly available in the west of India. The shrimp processing produces a large quantities of head and shell waste accounts approximately to $40-50 \%$. In India, shrimp processing plants produces more than 1 lakh tons of shrimp wastes annually (Kumar \& Suresh 2014). The waste generation from seafood processing especially crustaceans creates the practical difficulties in disposal and environmental pollution. Shrimp's head generally constitutes $34-45 \%$ and body shell constitutes 10-15\%. These wastes contain 35$40 \%$ protein, $10-15 \%$ chitin, $10-15 \%$ minerals and carotenoids (Sachindra and Bhaskar, 2008). Proper usage of shrimp shell wastes for the conversion of chitin and chitosan leads to economic gain to the producer. Apart from that, it reduces the unwanted environmental pollution by dumping the waste in open environment. So this present study was intended to study the structural and physicochemical properties of chitosan prepared from the Parapeneopsis stylifera shrimp shell waste.

\section{Materials and Methods}

\section{Preparation of chitosan from shrimp shell waste}

Chitosan from the shrimp shell was prepared using the method described by Benhabiles et al., (2012). The shrimp shell wastes were thoroughly washed in potable running water and cooked for $1 \mathrm{~h}$ to remove the adherent tissues and impurities. The washed shells were dried and ground into powder. Demineralization of shell was done using 1.5 $\mathrm{M} \mathrm{HCl}(1: 10 \mathrm{w} / \mathrm{v})$ for $30 \mathrm{~min}$ at room temperature. The decalcified shell were repeatedly washed with water to remove the 
acid and dried at $80^{\circ} \mathrm{C}$. Deproteinization was done using $2 \mathrm{~N} \mathrm{NaOH}(1: 10 \mathrm{w} / \mathrm{v})$ for $2 \mathrm{hr}$ at $40^{\circ} \mathrm{C}$ followed by washed with water and dried. This chitin was converted into chitosan by deacetylation using $50 \% \mathrm{NaOH}$ at the chitin and $\mathrm{NaOH}$ ratio of $1: 10$ at $90^{\circ} \mathrm{C}$ for $3 \mathrm{hr}$. Finally the solid was filtered, neutralized by washing with water and $80 \%$ alcohol and dried at $80^{\circ} \mathrm{C}$ overnight.

Moisture, protein, ash content and $\mathrm{pH}$ of Chitosan

Moisture content was analysed as per AOAC method (2000) using hot air oven. Crude protein content of chitosan estimated using the Kjeldhal method (AOAC, 2000). Ash content was determined as per the standard method (AOAC, 2000). The $\mathrm{pH}$ was determined using a digital $\mathrm{pH}$ meter.

\section{Fourier transform infrared spectroscopy (FTIR) analysis}

FTIR spectral data of the chitosan was obtained using FTIR spectrometer (iS5 NICOLET, Thermo Scientific, USA). The absorbance spectra of pellet were measured from $400-4000 \mathrm{~cm}^{-1}$. Spectrum signals were collected in 36 scans at a resolution of $4 \mathrm{~cm}^{-1}$. Spectral data analysis of was done with the help of OMNIC 9.0 software programme.

\section{Determination of degree of deacetylation (DD)}

The degree of deacetylation (DD) was determined by Fourier transform infrared spectroscopy (FTIR) data. The degree of acetylation (DA) was calculated by following Moore and Roberts (1980) equation:

\section{$D A=\left[\left(A_{1655} / A_{3450}\right) \times 100\right] / 1.33$}

where $\mathrm{A}_{1655}$ and $\mathrm{A}_{3450}$ are the absorbance intensity of respective wavelengths;
1.33 is the ratio of the absorbance at 1655 $\mathrm{cm}^{-1}$ to that of $3450 \mathrm{~cm}^{-1}$ for fully $\mathrm{N}$ acetylated chitosan.

Degree of deacetylation (DD) was calculated using the following formula:

$D D(\%)=100-D A(\%)$

\section{Determination of molecular weight of chitosan}

The viscosity-average molecular weight of the chitosan was determined by viscometric method described by Roberts and Domszy (1982). Chitosan was dissolved in $0.2 \mathrm{M}$ acetic acid with various concentrations $(0.5 \mathrm{mg} / \mathrm{ml}$, $1 \mathrm{mg} / \mathrm{ml}$ and $1.5 \mathrm{mg} / \mathrm{ml}$ ).

The viscosity was measured at $25^{\circ} \mathrm{C}$ using an Ostwald glass viscometer (Brosil, India). The molecular weight of chitosan was calculated using the following Mark-Houwink equation:

\section{Intrinsic viscosity $(\eta)=K(M W)^{a}$}

where $\mathrm{K}=1.81 \times 10^{-3}$, and $\mathrm{a}=0.93$

\section{Solubility}

Solubility of chitosan in weak acidic solution was measured following the method of Ahing and Wid (2016). One gram of chitosan was dissolved in $1 \%$ acetic acid solution to make $1 \%$ chitosan solution. This mixture was stirred using magnetic stirrer for $2 \mathrm{~h}$ at room temperature. The mixture was filtered through a pre-weighed Whatman No. 1 filter paper $\left(W_{i}\right)$. Then, filter paper was dried at ambient temperature and re-weighed $\left(W_{f}\right)$. The solubility percentage was calculated by using the following formula:

$$
\begin{aligned}
& \text { Solubility } \\
& =100-\left[\left(\frac{w_{f}-w_{i}}{w_{s}}\right) \times 100\right]
\end{aligned}
$$


where, $\left(W_{f}\right.$ - final weight of filter paper $(\mathrm{g}), W_{i}$ - initial weight of filter paper $(\mathrm{g})$ and $W_{s}$ chitosan weight $(\mathrm{g})$.

Water Binding Capacity (WBC) and Fat Binding Capacity (FBC) of chitosan

Water binding capacity (WBC) and fat binding capacity (FBC) of chitosan were determined according to the method described by Wang and Kinsella (1976) with slight modification. For WBC or FBC, weight of 50 $\mathrm{ml}$ capacity centrifuge tube with $1 \mathrm{~g}$ of sample was measured followed by $20 \mathrm{ml}$ distilled water or vegetable oil was added. Both tubes solutions were mixed for $5 \mathrm{~s}$ at every $10 \mathrm{~min}$. After one hour, the resulting solutions were centrifuged at $3200 \mathrm{rpm}$ for $25 \mathrm{~min}$ at room temperature. The supernatant was removed and the tube weight was measured. WBC and FBC were determined by using the following formula:

$W B C(\%)$

$=\frac{\text { Water bound sample }(g)}{\text { Initial weight of the sample }(g)} \times 100$

FBC $(\%)$

$=\frac{\text { fat bound sample }(g)}{\text { Initial weight of the sample }(g)} \times 100$

\section{Results and Discussion}

\section{Moisture, protein, ash and $\mathrm{pH}$ of chitosan}

The efficiency all the process involved in chitosan preparation from the shrimp shell waste viz., demineralization, Deproteinization and deacetylation was determined by the biochemical quality analysis. The moisture, protein, ash content and $\mathrm{pH}$ of the chitosan are shown in the Table 1. The yield of chitosan was $4.41 \%$. The moisture content of the chitosan was reported as $6.24 \%$. Better shelf life of chitosan was achieved by maintain the moisture content below 10\% (Nouri et al.,
2016; Li, 1992). In this study the ash content of chitosan was $0.39 \%$. The limit of ash content in high quality chitosan was less than 1\% (No and Meyers, 1995). Moreover, ash content of the chitosan directly correlates with the effectiveness of demineralization process. Protein content of the chitosan was $1.99 \%$. It indicates the effectiveness of Deproteinization during the chitosan production. $\mathrm{pH}$ of commercial chitosan is around 8 and in our present study it is noticed that the $\mathrm{pH}$ of chitosan prepared from shrimp shell was 7.9.

\section{FTIR analysis}

FTIR spectrum is based on the vibration of the atoms in the molecule. The FTIR spectrum of chitosan is shown in Figure 1. The absences of sharp band above the region of $3500 \mathrm{~cm}^{-1}$ explained the presence of intra-inter molecular hydrogen band in the hydroxyl group in $\mathrm{C}_{2}$ and $\mathrm{C}_{6}$ position of chitosan (Kumirska et al., 2010).

The peak above $3000 \mathrm{~cm}^{-1}$ in this chitosan was centred at $3444 \mathrm{~cm}^{-1}$. This higher frequency shift revealed a higher order structure present in this chitosan sample. According to kumar et al.,2004 the appearance of single broad peak at around $3371 \mathrm{~cm}^{-1}$ conform the presence of $\beta$ structure in the chitosan.

The peak around $2882 \mathrm{~cm}^{-1}$ was representing the presence of glucosamine in chitosan. Amide I peak present at $1653 \mathrm{~cm}^{-1}$ was denoting the $\mathrm{C}=\mathrm{O}$ stretching in chitosan and it was mainly due to hydrogen bonding (Nouri et al.,2016). Amide II peak represents the N-H bending and it was present at $1596 \mathrm{~cm}^{-1}$ in this chitosan sample. Generally amide III peak in chitosan is around $1320 \mathrm{~cm}^{-1}$. This peak indicates the presence of $n$ acetyl glucosamine in chitosan molecule (Brugnerotto et al., 2001). In this study the amide III chitosan was at $1323 \mathrm{~cm}^{-1}$. The peak at $1379 \mathrm{~cm}^{-1}$ represented the presence of asymmetrical $\mathrm{C}-\mathrm{H}$ bending of the $\mathrm{CH} 2$ group in chitosan. In 
polysaccharides $\mathrm{CH}_{2}$ bending is represented by the presence of peak near $1429 \mathrm{~cm}^{-1}$. In this sample it was present at $1421 \mathrm{~cm}^{-1}$.

\section{Degree of Deacetylation (DD) of chitosan}

The ratio between the glucosamine and $\mathrm{N}$ acetyl glucosamine is called degree of acetylation (DD). The conversion of chitin into chitosan was determined by the amount of formation of glucosamine content. Therefore, the higher the glucosamine content higher the degree deacetylation of chitosan. The study revealed that DD of the chitosan using FTIR method was $76.43 \%$. When the degree of deacetylation reaches $50 \%$, chitosan is readily dissolved in weak acids. DD is mainly influenced by the concentration of $\mathrm{NaOH}$ and temperature used for Deacetylation (Hargono and Djaeni, 2003). DD determines the molecular weight, viscosity, solubility and chemical reactivity. As per the previous studies, the DD may varies from $30 \%$ to $95 \%$ depends on the species and method of preparation. It is rare to achieve the 100\% DD (Islam et al., 2011).

\section{Molecular weight of chitosan}

Average molecular weight of the chitosan estimated by using intrinsic viscosity was 110.64 KDa (Table 1). Chitin identified as a higher molecular weight polysaccharides. Generally molecular weight of the chitosan is above one million, while commercial chitosan products have $100 \mathrm{KDa}$ to1200 $\mathrm{KDa}$ (Struszczyk et al., 2002). Molecular weight of chitosan determines the functional properties of chitosan. The molecular weight of chitosan influenced by the concentration of $\mathrm{NaOH}$, time temperature and substrate solvent ratio (Rout,2001). Moreover, viscosity of the chitosan is proportional to the molecular weight of chitosan.

\section{Solubility of chitosan}

Solubility plays a major role in the determination of chitosan quality. Good quality of chitosan has higher solubility. The prepared chitosan showed $98.4 \%$ solubility in $1 \%$ acidic acid solution. Solubility of chitosan was influenced by degree of deacetylation because the solubility is related to the elimination of acetyl group from the chitosan. Apart from that several factors such as time and temperature of deacetylation, alkali concentration and ratio of deprotenization, alkali concentration and ratio of chitosan production from chitin and size of the chitosan particle are also influence on the chitosan solubility (Hossain and Iqbal, 2014).

\section{Water Binding Capacity (WBC) and Fat Binding Capacity (FBC) of Chitosan}

The molecular weight of plays a major role in the functional properties of chitosan. In the present study the fat binding capacity of chitosan $331.28 \%$ whereas the water binding capacity was $637.33 \%$. WBC of commercial chitosan ranges between 581 to $1150 \%$ and the fat uptake of chitosan ranges from 315 to $170 \%$ (Rout, 2001; Knorr, 1982). WBC of chitosan was also influenced by the dissimilarities in crystallinity, availability of salt forming groups, and the residual protein present in the chitosan (Knorr, 1982). Viscosity may influence on the FBC of chitosan. The decreased viscosity of chitosan may be responsible for the lower fat binding capacity (Rout, 2001).

Shrimp shell wastes generated from shrimp processing industries consist of several valuable compound like chitin, chitosan and pigments and are generally discarded as waste into the environmental cause severe environmental problem. 
Table.1 Parameters analyzed for chitosan extracted from shrimp shell wastes

\begin{tabular}{cc}
\hline Parameters & Chitosan \\
\hline Yield & $4.41 \pm 1.22$ \\
Moisture & $6.24 \pm 1.01$ \\
Protein & $1.99 \pm 0.29$ \\
Ash & $0.39 \pm 0.14$ \\
pH & $7.9 \pm 0.11$ \\
DD & $76.43 \pm 0.91$ \\
Molecular weight (KDa) & $110.64 \pm 1.65$ \\
Solubility & $98.40 \pm 0.54$ \\
WBC & $637.33 \pm 2.54$ \\
FBC & $331.28 \pm 3.24$ \\
\hline
\end{tabular}

Fig.1 Caption: FTIR spectra of chitosan prepared from shrimp shell waste

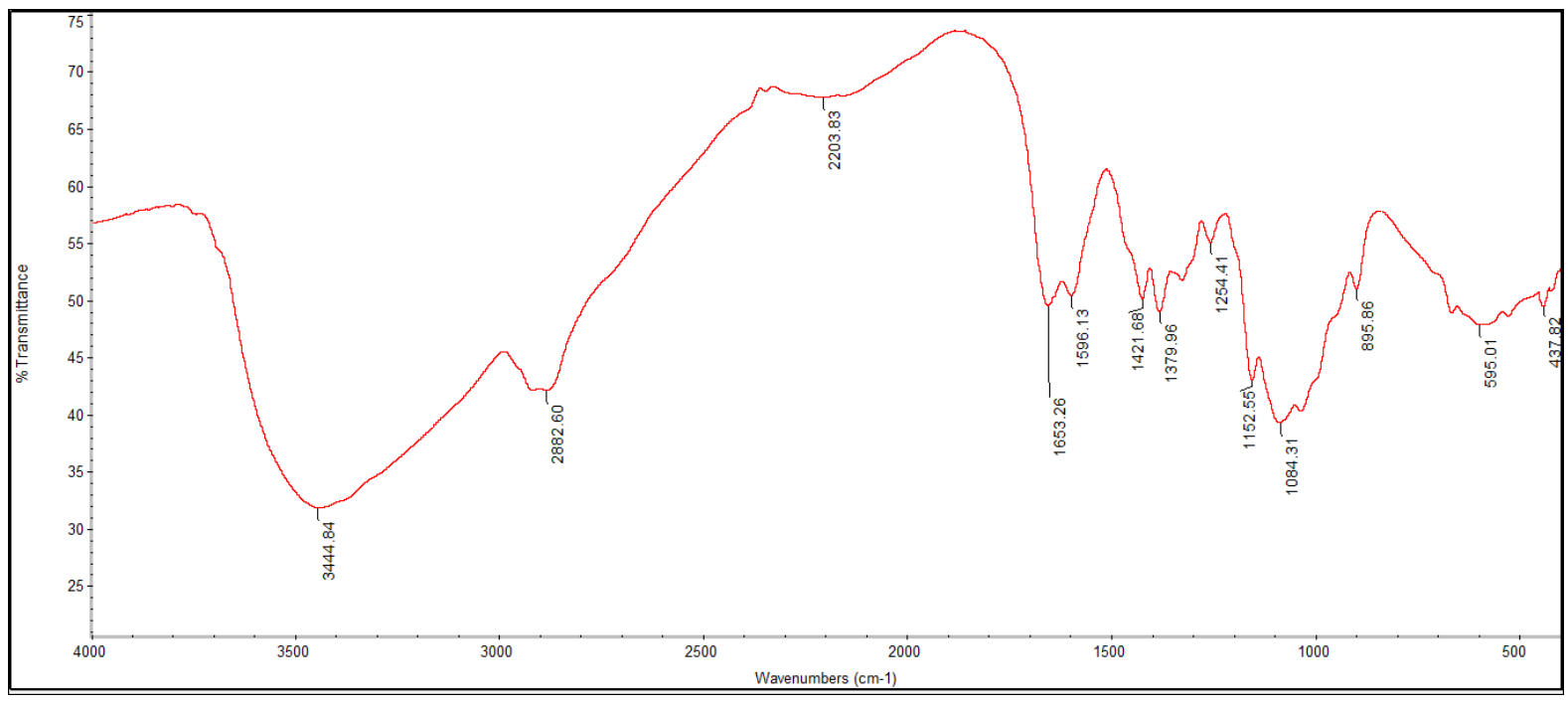

By utilizing these wastes for the production of chitin or chitosan pave a new path to better use of shrimp wastes and lead a way to cleaner environment. In this study shrimp shell wastes generated from the processing factories in Veraval region was utilized for the production of chitosan and their characteristics were studied. In summary, the physiochemical, functional and structural characteristic of chitosan properties were accordance with the chitosan studied by several authors. Hence, the chitosan could be a raw material for food, agricultural, medical or other industrial applications.

\section{Acknowledgement}

Authors would convey their thanks to the supporting and technical staffs, ICAR-CIFT Veraval research centre for their support and assistance.

\section{References}

Ahing, F.L., and Wid, N. 2016. Extraction and characterization of chitosan from shrimp shell waste in Sabah. Transactions on Science and Technology. 3(1-2), 227 - 237

AOAC. 2000. Official Methods of Analysis, 
17th Ed., Association of Official Chemists, Gaithersburg, MD.

Benhabiles, M.S., Salah, R., Lounici, H., Drouiche, N., Goosen, M.F.A., and Mameri, N. 2012. Antibacterial activity of chitin, chitosan and its oligomers prepared from shrimp shell waste. Food hydrocolloids. 29(1): 4856.

Brugnerotto, J., Lizardi, J., Goycoolea, F.M., Argüelles-Monal, W., Desbrieres, J., and Rinaudo, M. 2001. An infrared investigation in relation with chitin and chitosan characterization. Polymer. 42(8): 3569-3580.

Crini, G. (2019). Historical Landmarks in the Discovery of Chitin In: Sustainable Agriculture Reviews 35, Springer, Cham. Pp. 1-47.

Hamed, I., Ozogul, F., and Regenstein, J.M. 2016. Industrial applications of crustacean by-products (chitin, chitosan, and chitooligosaccharides): A review. Trends in Food Science \& Technology. 48: 40-50.

Hargono, H., and Djaeni, M. 2003. Utilization of chitosan prepared from shrimp shell as fat diluent. Journal of Coastal Development, 7(1), pp.31-37.

Hossain, M.S., and Iqbal, A. 2014. Production and characterization of chitosan from shrimp waste. Journal of the Bangladesh Agricultural University. 12(1): 153-160.

Islam, M.M., Masum, S.M., Rahman, M.M., Molla, M.A.I., Shaikh, A.A., and Roy, S.K. 2011. Preparation of chitosan from shrimp shell and investigation of its properties. International Journal of Basic \& Applied Sciences. 11(1): 7780.

Knorr, D. 1982. Functional properties of chitin and chitosan. Journal of Food Science. 47(2): 593-595.

Kumar, A.V. and Tharanathan, R.N. 2004. A comparative study on depolymerization of chitosan by proteolytic enzymes. Carbohydrate Polymers, 58(3): 275-283.

Kumirska, J., Czerwicka, M., Kaczyński, Z., Bychowska, A., Brzozowski, K., Thöming, J., and Stepnowski, P. 2010. Application of spectroscopic methods for structural analysis of chitin and chitosan. Marine drugs. 8(5): 15671636.

Li, Q., Dunn, E.T., Grandmaison, E.W. and Goosen, M.F. 1992. Applications and properties of chitosan. Journal of Bioactive and Compatible Polymers. 7(4): 370-397.

Moore, G.K., and Roberts, G.A. 1980. Determination of the degree of $\mathrm{N}$ acetylation of chitosan. International Journal of Biological Macromolecules. 2(2): 115-116.

MPEDA. The Marine Products Export Development Authority annual report 2017-2018. (2018). http://mpeda.gov.in/MPEDA/admin/ap p/webroot/files/annualreport/15501205 14MPEDAAR201718.pdf/ Accessed 10 October 2019.

No, H.K., and Meyers, S.P. 1995. Preparation and characterization of chitin and chitosan-a review. Journal of aquatic food product technology. 4(2): 27-52.

Nouri, M., Khodaiyan, F., Razavi, S.H. and Mousavi, M. 2016. Improvement of chitosan production from Persian Gulf shrimp waste by response surface methodology. Food Hydrocolloids. 59: 50-58.

Roberts, G.A., and Domszy, J.G. 1982. Determination of the viscometric constants for chitosan. International Journal of Biological Macromolecules. 4(6): 374-377.

Rout, S.K. 2001. Physicochemical, Functional and Spectroscopic Analysis of Crawfish Chitin and Chitosan as Affected by Process Modification. 
Dissertation, Louisiana State chitosan. Polimery. 47(5): 316-325. University and Agricultural \& Wang, J.C., and Kinsella, J.E. 1976. Mechanical College, USA.

Sachindra, N.M., and Bhaskar, N. 2008. In vitro antioxidant activity of liquor from fermented shrimp biowaste. Bioresource Technology. 99(18): 9013-9016.

Struszczyk, M.H., Pośpieszny, H. and Gamzazade, A., 2002. Chitin and Functional properties of novel proteins: Alfalfa leaf protein. Journal of food science. 41(2): 286-292.

Younes, I., and Rinaudo, M. 2015. Chitin and chitosan preparation from marine sources: Structure, properties and applications. Marine drugs. 13(3): $1133-1174$.

\section{How to cite this article:}

Vijayakumar Renuka, Chandragiri Nagaraja Rao Ravishankar, Krishnamoorthy Elavarasan, Abubacker Aliyamveetil Zynudheen and Toms C. Joseph. 2019. Production and Characterization of Chitosan from Shrimp Shell Waste of Parapeneopsis stylifera. Int.J.Curr.Microbiol.App.Sci. 8(11): 2076-2083. doi: https://doi.org/10.20546/ijcmas.2019.811.240 